\title{
THE ROLE OF LIGAMENTUM FLAVUM CALCIFICATION AT LUMBAR SPINE CAUSING CAUDA EQUINA SYNDROME AND LUMBAR RADICULOPATHY: CASE REPORT
}

Gajanan Deshmukh ${ }^{1}$

\section{HOW TO CITE THIS ARTICLE:}

Gajanan Deshmukh. "The role of ligamentum flavum calcification at lumbar spine causing cauda equina syndrome and lumbar radiculopathy: case report". Journal of Evolution of Medical and Dental Sciences 2013; Vol. 2, Issue 42, October 21; Page: 8150-8155.

ABSTRACT: The focal calcification or ossification of ligamentum flavum is a rare cause of thoracic myelopathy and most often occurs among individuals of Japanese descent. It is rare in other ethnic groups and in individuals below the age of 50 year. It is most often described at the lower thoracic level, being uncommon in the lumbar region and rare in the cervical region. Here, we present the case of a 40-year-old Indian female patient who sought medical attention with a six month history of paraesthesia of the lower limbs and progressive difficulty in walking. The clinical profile, together with computed tomography and magnetic resonance imaging of the spine, led to a diagnosis of compressive lumbar myelopathy due to ossification of the ligamentum flavum of lumbar spine. The patient underwent laminectomy and dissection of some of the affected ligamentum flavum. After three months of clinical follow-up, the patient had progressed favorably, having no sensory complaints and again becoming ambulatory.

CASE REPORT: A previously healthy 40-year-old female patient sought medical attention at our hospital. The patient presented with a 2-month history of ascending paraesthesia of the left leg, with progressive worsening and right leg involvement, accompanied by reduced (right and left) leg muscle strength. She reported lower back discomfort. She also found difficulty in sitting and walking showing signs of neurological claudication. Neurological examination revealed paraparesis.

A computed tomography (CT) scan of the lumbar spine revealed the following: calcification of ligament flavum at L2-L3 to L4-L5 levels worst at L3-L4 and lateral recess stenosis at L3-L4 and L4-L5.
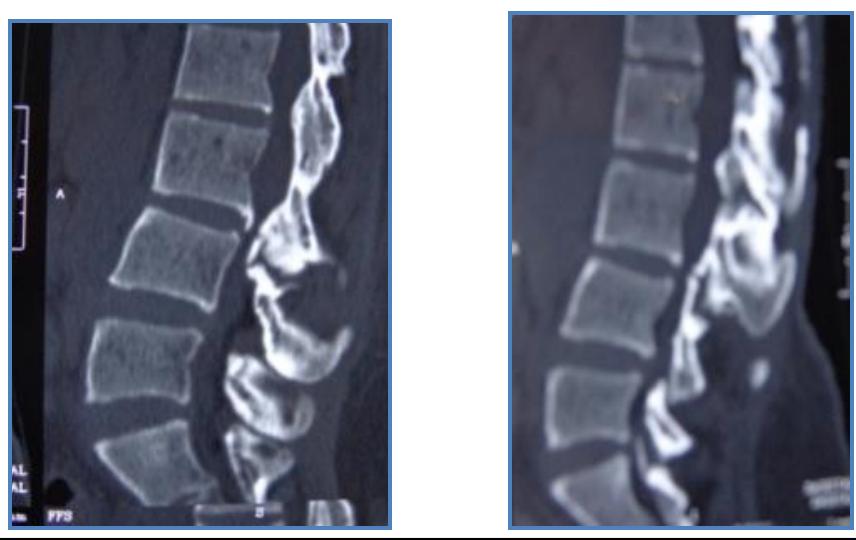

Fig.1 \& 2: CT scan shows ligament flavum calcification 


\section{CASE REPORT}
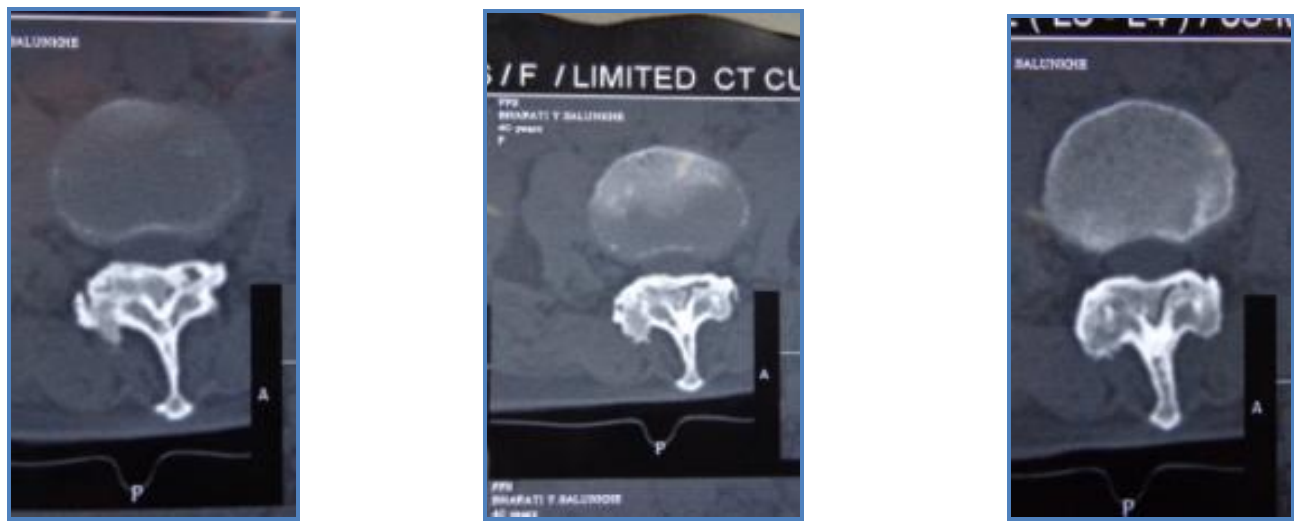

Fig 3, 4, 5: Axial CT scan at L3-L4 AND L4-L5: CALCIFIED LIGAMENTUM FLAVUM. WITH LATERAL STENOSIS

Magnetic resonance imaging (MRI) showed diffuse bulge with bilateral foraminal components of L4 -L5 disc with ligamentum flavum hypertrophy and facetal arthropathy, diffuse bulge of L3-L4 disc, also marked ligamentum flavum hypertrophy and thickening at L3 -L4.
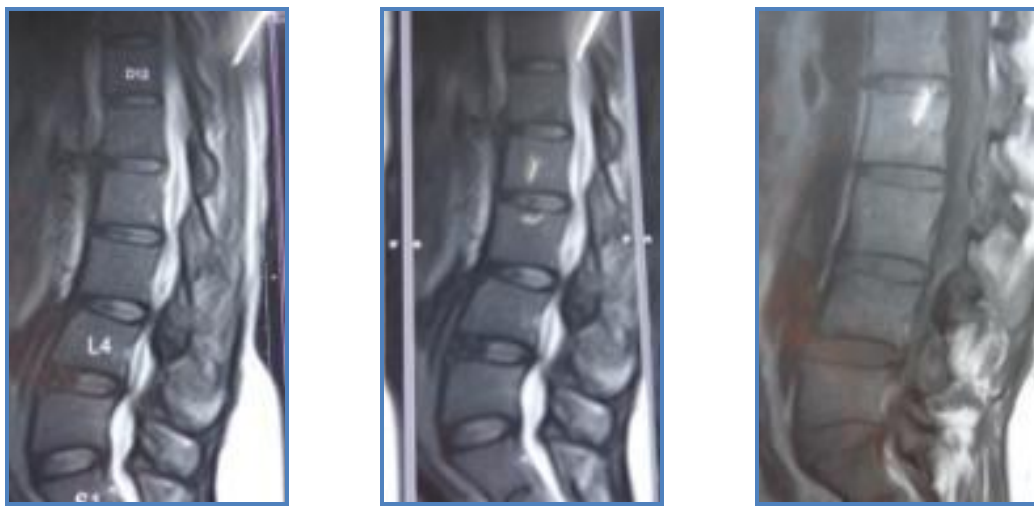

Fig 6: Mid-sagittal T2 weighted image showing spinal cord compression at the L3-L4 level, with abnormal hyper intensity within cord parenchyma
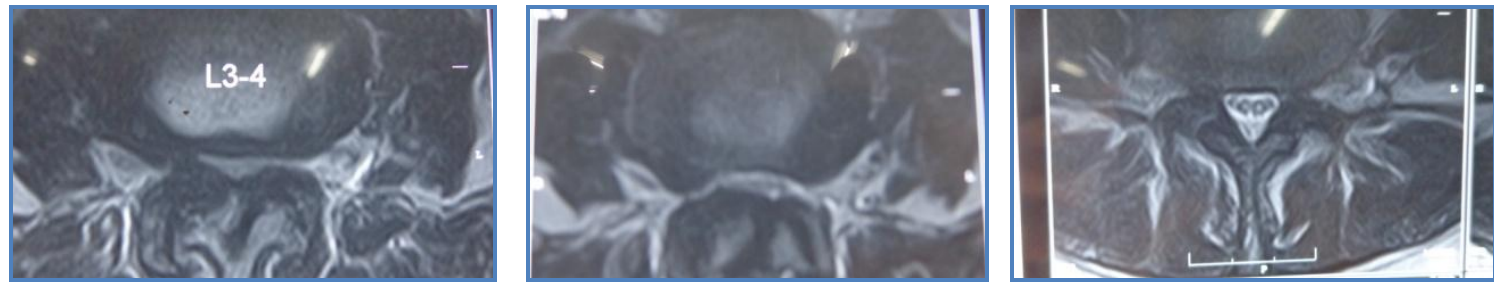

Fig 7: Axial view at L3-L4: ligamentum Flavum Thickening with Lateral Recess Stenosis 


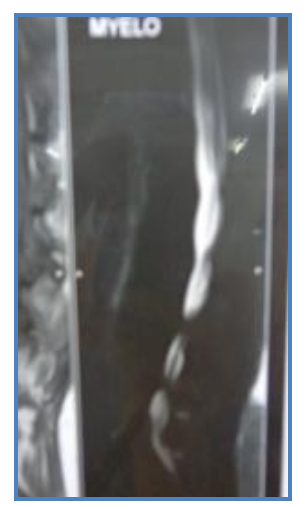

Fig 8: MRI Myelogram: stenosis at L3-L4 and L4-L5 Extradural Compression

Laboratory test results were normal, metabolic disorders being therefore ruled out.

The patient underwent laminectomy and dissection of some of the affected LF. Intra operatively lamina was found to be much harder and it was very difficult to excise. Ligamentum flavum was adhered to duramater. While excising flavum dura was ruptured and there was leakage of CSF through rent. Dura was repaired to stop CSF leak. Decompression was adequately achieved at L3 to L5.

After six months of clinical follow-up, the patient had progressed favorably, having no sensory complaints and again becoming ambulatory.
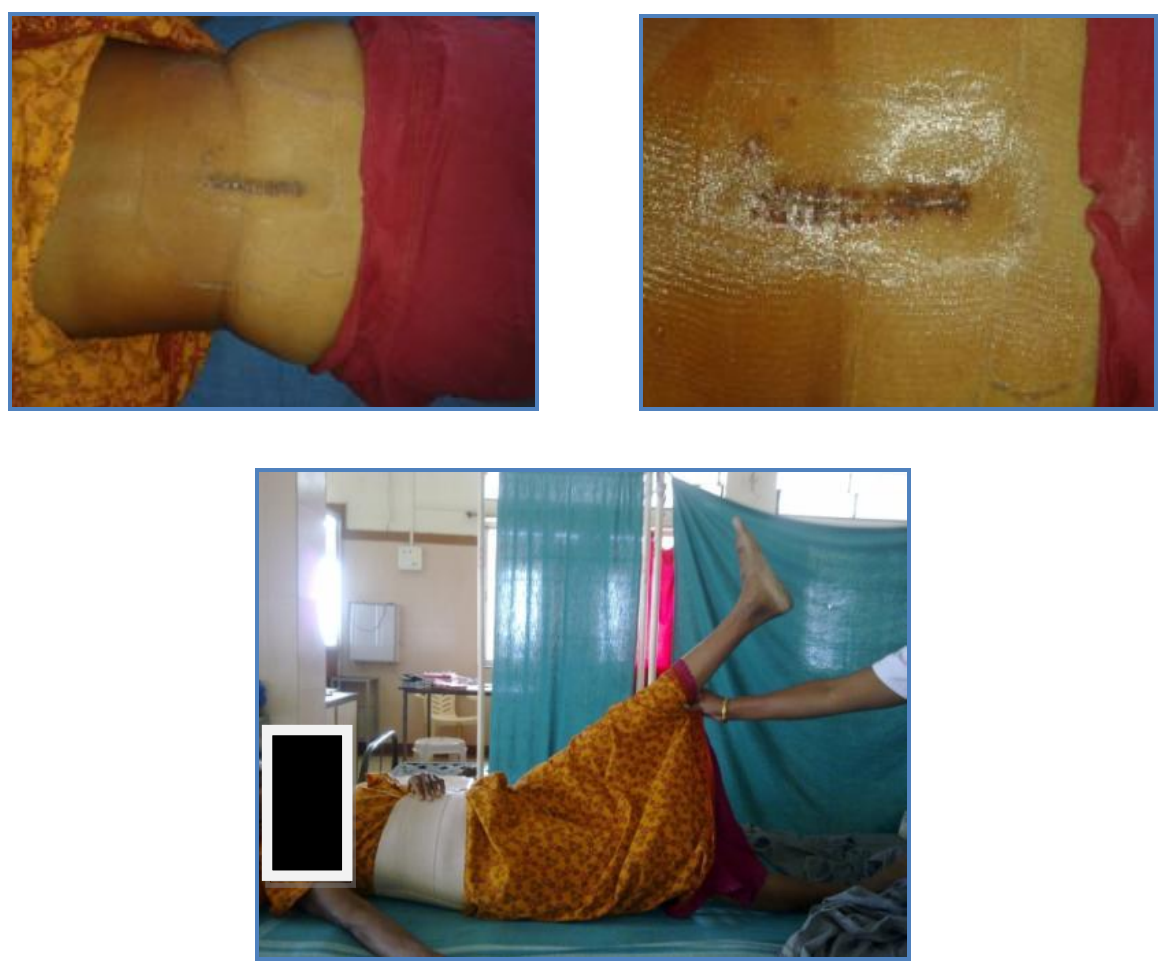

$12^{\text {th }}$ post operative day: active SLR pian upto 70 degree painfree further painful. Before surgery patient could not do same because of pain. 


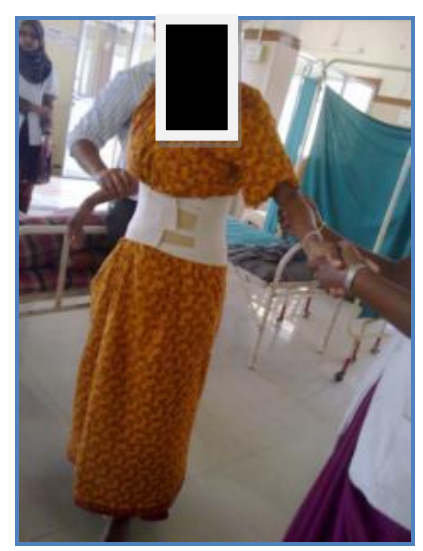

Clinical photo on $12^{\text {th }}$ post op day: patient could able to walk with assistance.
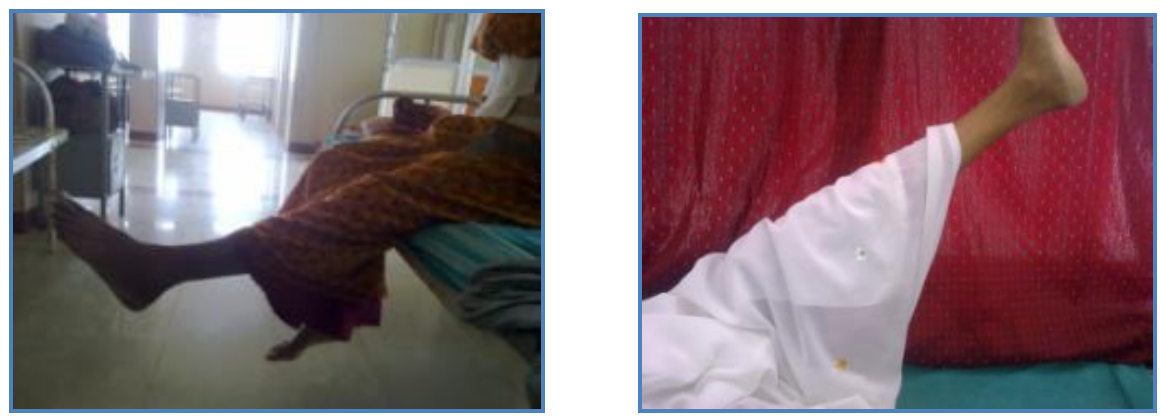

Patient regained muscle power in quadriceps above 3 (MRC) post operatively. 4 month post operative follow up: pain free active SLRT.
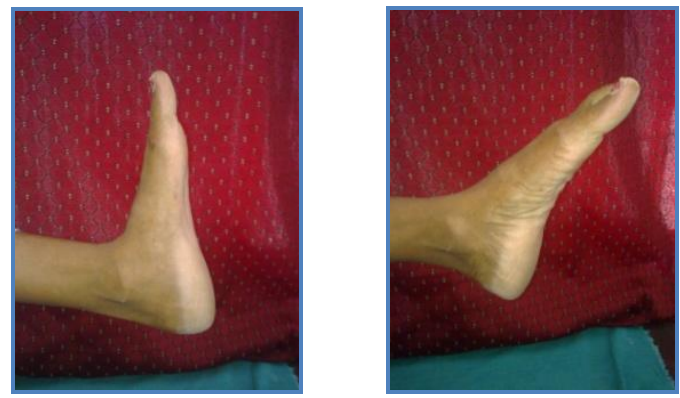

Active ankle movement: planter flexion and dorsiflexion

DISCUSSION: Although uncommon, ossification or calcification of the ligamentum flavum as a cause of thoracolumbar myelopathy has been extensively described in Eastern populations, particularly in individuals of Japanese descent ${ }^{1-7}$.But in Indian population ligamentum flavum hypertrophy due to ligamentum flavum ossification and calcification is rare.

The ligamentum flavum are elastic connective tissue ligaments that lie on a crest bone located on the lower border of the vertebral lamina, extending to the upper border of the lamina of the underlying vertebral body and contributing to forming the posterior limit of the intervertebral foramen. The elasticity of the ligamentum flavum decreases with age. Histologically, there is a variety of pathological conditions affecting the ligamentum flavum including hypertrophy, calcification, and ossification. In cases of hypertrophy, the normal fibrous structure of the 
ligamentum flavum is replaced by hypertrophic fibrous tissue containing numerous fibrocartilaginous cells with abundant matrix ${ }^{9}$. Such calcification consists of thickening of the deep layers of the LF, whereas the corresponding ossification affects only the most superficial layers 10 .

Ossification or calcification of the ligamentum flavum is an idiopathic endochondral calcification that affects approximately $20 \%$ of individuals who are of Eastern origin and who are older than 60 years of age ${ }^{11}$, being rare in those who are not of Eastern origin and in those who are younger than 50 years. Ossification or calcification of the ligamentum flavum can be associated with Paget's disease, rickets, chondrocalcinosis, ankylosing spondylitis, hypoparathyroidism, skeletal hyperostosis, obesity, diabetes, hyperinsulinemia, and disorders of calcium metabolism ${ }^{11}$.

$\mathrm{X}$-ray and myelography findings can suggest the diagnosis. The two methods generally have limited value. A CT scan can reveal a calcified/ ossified extradural mass located under the vertebral lamina and protruding into the intervertebral foramen, with a loss of extradural fat 11 .In determining the degree of spinal cord compression and the characteristics of ossification, MRI is extremely useful, the ligamentum flavum appearing hypointense on T1- and T2-weighted images. The typical indentation is best seen on T2-weighted images ${ }^{11}$.The use of CT and MRI in combination provides information that is more accurate and useful for treatment planning than does the use of either alone $^{4-9}$.

The treatment of ossification or calcification of the ligamentum flavum generally consists of posterior surgical decompression by laminectomy or laminoplasty with joint preservation, which increases the stability of the spinal column ${ }^{11}$. The prognosis is variable but typically favourable. However, the course of the disease is sometimes severe because of the size and extent of the stenosis ${ }^{12}$. Nevertheless, a physical therapy rehabilitation program should be started gradually, as early as in the immediate postoperative period ${ }^{11-12}$.

CONCLUSION: Calcification of ligamentum flavum at thoracolumbar and cervical region is common in eastern population like Japanese. It is quite rare in Indian population. Ossification or calcification of the ligamentum flavum at lumbar spine can lead to spinal cord compression due to spinal canal stenosis presenting as cauda equina syndrome or as neurological claudication. CT remains the investigation of choice to demonstrate ossification. Spinal MRI shows hypertrophy of ligamentum flavum causing spinal cord compression ${ }^{13}$. The diagnosis is preferably made by MRI and CT in combination ${ }^{12-13}$. The prognosis is variable, sometimes being poor because of the size and extent of stenosis. The treatment of ossification or calcification of the ligamentum flavum at lumbar spine generally consists of posterior surgical decompression by laminectomy or laminoplasty.

Isolated ligamentum flavum calcification at lumbar spine is rare and can present to you as spinal canal stenosis which is easily diagnosed by combination of CT and MRI and can be treated by laminectomy.

\section{REFERENCES:}

1. Kubota M, Baba I, Sumita T. Myelopathy due to ossification of the ligamentum flavum of the cervical spine: a report of two cases. Spine. 1981; 6:553-9. PMid: 6801782. http:// dx.doi.org/10.1097/00007632-198111000-00005.

2. Takayama S, Kuribayashi K, Miyamoto Y, Nakasu Y, Handa J. Ossification and calcification of the cervical ligamentum flavum. No To Shinkei. 1993; 9:859-63. 
3. Yoshida H, Murao S, Nakajima T, Tsutsumi T. Paraplegia caused by ossification of the ligamentum flavum. Nippon Rinsho. 1976; 10:3085-90.

4. Hanakita J, Suwa H, Ohta F, Nishi S, Sakaida H, Iihara K. Neuroradiological examination of thoracic radiculo-myelopathy due to ossification of ligamentum flavum. Neuroradiology. 1990; 32:38-42. PMid: 2110325. http:// dx.doi.org/10.1007/BF00593939.

5. Hukuda S, Mochizuki T, Ogata M, Schichikawa K. The pattern of spinal and extra spinal hyperostosis in patients with ossification of the posterior longitudinal ligament and the ligamentum flavum causing myelopathy. Skeletal Radiol. 1983; 10:79-85. PMid: 6612370. http://dx.doi. org/10.1007/BF00360789.

6. Myakasa K, Kaneda K, Sato S, et al. Myelopathy due to ossification or calcification of the ligamentum flavum: Myakasa K, Kaneda K, Sato S, et al. Myelopathy due to ossification or calcification of the ligamentum flavum:

7. Yamashita Y, Takahashi M, Matsuno Y, et al. Spinal cord compression due to ossification of ligaments: MR imaging. Radiology. 1990; 175:843-8. PMid: 2111569.

8. Johnson RM, Murphy MJ, Sothwick WO. Surgical approaches to the spine. In: Rothman RH, Simeone FA, editors. The Spine. 3rd ed. Philadelphia: WB Saunders; 1992. p. 1623-8.

9. Okada K, Oka S, Tohge K, Ono K, Tunenobu K, Hosoya T. Thoracic myelopathy caused by ossification of the ligamentum flavum. Spine. 1991; 16:280-7. PMid: 1902988. http://dx.doi.org/10.1097/00007632-199103000-00005.

10. Akino M, Abe H, Iwasaki Y, et al. A case of cervical myelopathy due to calcified mass in the cervical yellow ligament. Neurol Surg (Tokyo). 1983; 11:173-8.

11. Gondim, J, Ramos Junior, F. Compressão medular torácica em dois níveis por calcificação de ligamento amarelo: relato de caso. Arq neuropsiquiatr. 1998; 56:312-6.

12. Martines JAS, Martines BMR, Araujo Filho JAB, Pinto LEA, Castro CC. Calcification of the ligamentum flavum in the thoracolumbar spine: an unusual cause of compressive myelopathy. Autopsy Case Rep [Internet]. 2012; 2(2):25-29.

13. Jaisuresh et Calicut medical journal $2007 ; 5 ;(5)$ : el.

\section{AUTHORS:}

1. Gajanan Deshmukh

\section{PARTICULARS OF CONTRIBUTORS:}

1. Assistant Professor, Department of Orthopaedics, Trauma and rehabilitation, Dr. Ulhas Patil Medical College, Jalgoan, Maharashtra, India.

\section{NAME ADDRESS EMAIL ID OF THE CORRESPONDING AUTHOR:}

Dr. Gajanan Deshmukh, Vrundavan Colony, Karegaon Raod Parbhani, Maharashtra.

Email-drgaju13@yahoo.com

Date of Submission: 03/10/2013.

Date of Peer Review: 04/10/2013.

Date of Acceptance: 07/10/2013.

Date of Publishing: 19/10/2013 